\title{
QUALIDADE DOS INTERNETBANKINGS SEGUNDO CARACTERÍSTICAS DOS USUÁRIOS QUALIDADE DOS INTERNETBANKINGS SEGUNDO CARACTERÍSTICAS DOS USUÁRIOS
}

Recebido em 17.03.2013. Aprovado em 30.10.2013

Avaliado pelo sistema double blind review

DOI: http://dx.doi.org/10.12712/rpca.v7i4.267

\author{
Luiz Alberto Marcondes Homen de Mello e Castro \\ castro.beto@gmail.com \\ Fundação Getúlio Vargas - Escola de Administração de Empresas de São Paulo FGV-EAESP - São Paulo - \\ SP-Brasil.
}

\section{Maria Aparecida Gouvêa}

magouvea@usp.br

Fundação Getúlio Vargas - Escola de Administração de Empresas de São Paulo FGV-EAESP - São Paulo SP-Brasil.

\section{Resumo}

Essa pesquisa foi realizada para se identificar a percepção dos clientes de Internetbanking em relação à sua qualidade. 0 estudo consistiu de um levantamento da percepção de 150 pessoas residentes na cidade de São Paulo e usuárias do netbanking do Abn Amro Real (Santander), Banco do Brasil, Bradesco, Itaú ou Unibanco. Foi feita uma adaptação do modelo SERVQUAL, denominada E-BANKING, e, por meio de análises estatísticas, verificou-se a confiabilidade e validade deste novo modelo. Ademais, aplicou-se a análise de correspondência para serem identificadas tendências de avaliação da qualidade do serviço relacionadas a variáveis socioeconômicas e de hábitos de uso. Os resultados deste estudo revelaram que o modelo desenvolvido é adequado para avaliar os netbankings e que os clientes do sexo masculino, com idade de 33 a 43 anos e que são usuários intensos desse canal de serviços são os que atribuem as maiores notas de qualidade para o Internetbanking.

Palavras-chave: Internetbanking, qualidade, serviços virtuais, E-BANKING, satisfaçao.

\section{Abstract}

This research was carried out in order to identify the perception of Internetbanking clients in relation to the quality of this service. The study consisted of a perception survey of 150 inhabitants in the city of São Paulo and users of the Internetbanking of Abn Amro Real (Santander), Banco do Brasil, Bradesco, Itaú ou Unibanco. An adaptation of SERVQUAL model, what was called E-BANKING, was made and it was verified the reliability and validity of this new model through the statistical analyses. Moreover, it was applied the correspondence analysis to identify the trends in the opinion related to service quality related to socioeconomic variables and usage habits. The results of this study showed that the model developed fits for Internetbanking evaluation and that clients of male gender, aging from 33 to 43 years and heavy users of this service channel are those that give the highest scores to the Internetbanking quality.

Keywords: Internetbanking, quality, virtual services, E-BANKING, satisfaction. 


\section{Introdução}

Desde a queda da taxa de inflação, que reduziu as margens de lucro, e da abertura comercial brasileira, as instituições financeiras têm enfrentado uma competitividade que tem exigido a execução de operações a custos reduzidos e a maior interação com os clientes, conectando-os na criação e desenvolvimento dos novos serviços bancários, a fim de oferecer-lhes soluções que os satisfaçam e fidelizem, o que traria o tão desejado aumento do número de serviços consumidos e, conseqüentemente, da lucratividade, por cliente, devido a economias de escopo.

Entre as possíveis soluções aventadas, a Internet foi a opção que tinha mais possibilidade de atender a atual necessidade das instituições financeiras. Assim, os bancos tornaram-se os maiores investidores em tecnologia de informação para apoiar os seus processos de negócio, buscar a eficiência empresarial e melhorar a qualidade dos seus serviços. Os investimentos pesados na Web contribuíram para a criação do Internetbanking, que oferece serviços financeiros on-line classificados em três categorias: divulgação de informações, transações e relacionamento com os clientes.

A adoção do netbanking por parte do setor bancário levou à profusão de sites desse sistema, o que tem demandado o planejamento e o desenvolvimento mais cuidadoso deles, de forma a atender os desejos e necessidades do mercado, a fim de se entregar um serviço com valor agregado maior que o dos concorrentes, obtendo, dessa forma, um diferencial competitivo em relação aos concorrentes e um maior brilho aos olhos do mercado pretendido.

Os bancos de maior porte e os estatais são os que têm investido mais na oferta de serviços na $W e b$, o que indica que os sites estão se tornando mais sofisticados, com uma oferta maior de serviços e, de modo geral, que o Internetbanking está se consolidando no segmento de varejo. Já os bancos menores parecem ainda tímidos na Web; porém os que resolvem investir nesse canal "gastam proporcionalmente mais do que os maiores em seus sites na Web. Isto mostra que, em valores absolutos, bancos de diferentes tamanhos investem em ordens de grandeza próximas quando se trata do canal Web" (DINIZ, 2001, p. 154).

Sendo a intenção dos bancos utilizarem-se dos serviços via Web como um meio de estreitamento do contato com os seus clientes, essas instituições devem se preocupar com a satisfação que consumidores estão tendo com o uso dos seus serviços virtuais (OHIRA; SCHENKEL; SILVEIRA, 2003).

Tal afirmação se justifica pela atual definição de marketing, a de que a empresa sobrevive e cresce ao satisfazer as necessidades dos clientes (KOTLER, 2000). Para estes, o Internetbanking chegou para ficar pela comodidade de pagar as contas em casa ou no trabalho, a qualquer hora do dia ou da noite (TANAAMI, 2002).

Desse modo, o principal objetivo deste estudo é a construção de um modelo que permita a identificação da percepção dos clientes em relação à qualidade dos serviços bancários via Internet e dos fatores que possuem maior poder discriminatório e de influência no sentimento referente à qualidade destes serviços. Pois, com a identificação dos aspectos comuns ao grupo de usuários satisfeitos e não-satisfeitos, descobrir-se-á qual é o perfil de usuário que é rentável para o banco, devendo, deste modo, ser alvejado e receber uma abordagem e tratamento diferenciado, já que são capazes de gerar mais lucro para o banco, ao utilizar um meio de transação mais barato.

Para o alcance desse objetivo geral, são definidas algumas metas específicas: 1) Construção de um modelo de avaliação da qualidade dos serviços bancários via Internet; 2) Aferição da confiabilidade e da validade do modelo adaptado; 3) Identificação das tendências de avaliação 


\section{QUALIDADE DOS INTERNETBANKINGS SEGUNDO CARACTERÍSTICAS DOS USUÁRIOS}

relacionadas a variáveis demográficas e de familiaridade com a Internet e o banco virtual.

\section{Internetbanking ou banco virtual}

Sucintamente, Fortuna (2002) define Internetbanking como toda e qualquer ligação entre o computador do cliente e o computador do banco, independente de modelo ou tamanho, que permita às partes se comunicarem à distância.

Numa visão mais abstrata e mercadológica, Bader (1999) considera o banco virtual como uma proposta de atendimento personalizado e distribuição de serviços bancários e não bancários, com um ferramental tecnológico utilizado por uma equipe treinada e capacitada a interagir transacional e negocialmente, a fim de proporcionar maior conveniência e gerar mais valor à relação cliente-banco, visando à superação das dificuldades que derivam da minimização do contato físico que é fundamental para a realização de negócios e fidelização da base de clientes.

Com uma visão, em linhas gerais, mais utilitarista do sistema, Diniz (2001) e Costa Filho (1996) definem o netbanking como qualquer solução de informática e de telecomunicações capaz de permitir o acesso personalizado e a distribuição de serviços bancários e não bancários, quando os clientes quiserem e de onde estiverem, sem que estes precisem locomover-se de suas casas ou escritórios até uma agência bancária, ou seja, prescindindo-se da rede de agências.

Diniz (2001) comenta sobre quatro razões para que os bancos se apressem na reestruturação em negócios on-line e aumentem o investimento para desenvolver melhores aplicações tecnológicas a fim de explorar o potencial de uso desses cyberbankings:

- Ninguém duvida que a Internet crescerá, a única questão é com que velocidade;

- Os bancos precisam se antecipar a qualquer ameaça vinda das novas operações on-line, principalmente aquelas que são especializadas e de baixo custo, que tirariam alguns negócios rentáveis do setor bancário;

- Eles precisam competir com os seus atuais bancos concorrentes off-line;

- Os acionistas dos bancos estão exigindo estratégias on-line.

Outra razão para se investir e desenvolver todo o potencial tecnológico disponível para o banco virtual são os benefícios oferecidos para os clientes, como a diminuição do tamanho das filas nas agências bancárias físicas, a maior flexibilidade horária para realizar as transações bancárias e o ganho de tempo em função da possibilidade de se realizarem as transações a partir de casa. Esse último beneficio foi comprovado em pesquisa realizada por Costa Filho (1996), na qual 87\% dos entrevistados o citaram. Além disso, estima-se que o processamento de uma transação eletrônica custa seis vezes menos que o custo de processar um cheque, além da obtenção de um maior número de clientes fidelizados e de negócios realizados, o que implicará aumento da lucratividade do banco.

Porém, para atingir esse eldorado prometido, os bancos devem estar atentos aos novos comportamentos e expectativas de seus clientes frente às novas realidades, como a globalização da economia, a interatividade no consumo e ampliação do comércio eletrônico e devem aumentar os investimentos, a fim de explorar toda a potencialidade e qualidade dos serviços que esse canal pode oferecer (DINIZ, 2001, p. 51). 


\section{Serviços de banking via Internet}

Sendo os serviços bancários direcionados para pessoas físicas, um relacionamento negócio-aconsumidor, eles são denominados de categoria de transações de mercado. Numa transação de mercado, de acordo com Albertin (2000:28), "os clientes aprendem sobre produtos [/serviços] por meio de publicação eletrônica; compram-nos, utilizando dinheiro e sistemas eletrônicos de pagamento seguros; e os têm entregue. Além disso, também estabelecem sua fidelidade". Ou seja, nesse tipo de negócio ocorrem três tipos básicos de serviço: 1) de divulgação de informações, 2) de transações bancárias e 3) de relacionamento com o cliente.

Os serviços na categoria divulgação são aqueles que transmitem informações da empresa para o público usuário, podendo ser utilizados tanto para a distribuição de informações de negócios quanto para promover a empresa e seus respectivos produtos/serviços (DINIZ, 2001), sendo que esta última função pode, segundo Albertin (2000), ser vista como um canal de marketing adicional, permitindo alcançar um número máximo de clientes. Em ambos os casos, a Web é utilizada como um canal para informar os usuários a partir de uma fonte de informações geradas na empresa.

Os serviços de transação bancária se caracterizam, de acordo com Diniz (2001, p. 69), pela

possibilidade de efetivação de uma troca entre empresa e usuário do site. Da mesma forma que ocorre em agências físicas, nos serviços desta categoria, para o usuário receber um benefício ele deve fornecer para a organização alguma informação que o habilite para tal. Isto ocorre numa transferência de fundos, por exemplo, quando o usuário apenas pode realizar o serviço desejado ao se identificar e definir os valores para efetuá-lo, configurando-se então uma troca entre a organização e o usuário.

Os serviços de relacionamento são identificados, segundo Diniz (2001, p. 69-70), "pela sua capacidade de coletar informações dos usuários. Nesta categoria estão os serviços desenvolvidos para ajudar o banco a conhecer mais sobre as necessidades dos usuários de seu site, suas expectativas e seus interesses".

Por fim, no ambiente da Web, DINIZ (2001, p. 70-71) divide cada uma dessas categorias de serviços, segundo o grau de interatividade, em três níveis:

No primeiro nível, denominado básico, a empresa apenas reproduz no Website as possibilidades que já explora em outros canais. A presença na Internet abre uma nova frente de atuação, mas ainda sem explorar todas as possibilidades específicas da Web. [...] estes serviços são apenas uma transposição para a Web daqueles já utilizados em outros canais.

No nível seguinte, o intermediário, algumas características especificas da Web já são utilizadas para incrementar os serviços oferecidos. Neste nível, [...] os serviços e produtos oferecidos tendem a ter um incremento de qualidade, embora ainda mantenham as características básicas daqueles oferecidos por outros canais. A adoção de serviços do nível intermediário, que exige um grau maior de interação com o usuário, forçará a organização se adaptar para responder às demandas específicas e direcionamento de informações coletadas dos usuários para outras áreas da empresa. No terceiro nível, o avançado, encontram-se as utilizações da Web que abrem possibilidades para a criação de novas oportunidades de negócio, com a oferta de serviços eletrônicos que inovam na relação da empresa com os usuários de seu site. 


\section{QUALIDADE DOS INTERNETBANKINGS SEGUNDO CARACTERÍSTICAS DOS USUÁRIOS}

\section{Estrutura de avaliação dos serviços virtuais}

Para a avaliação da qualidade dos serviços bancários via Internet, ou Internetbankings, cogitou-se na utilização de dois modelos reconhecidos como válidos e confiáveis, o Modelo de Aceitação de Tecnologia (TAM) e o Modelo SERVQUAL.

\section{Modelo TAM}

O Modelo de Aceitação de Tecnologia (TAM - Technology Acceptance Model) foi proposto por Davis (1986). A principal finalidade do Modelo de Aceitação de Tecnologia é prever e explicar a aceitação de novas tecnologias pelo seu usuário final, por meio de crenças percebidas (utilidade e facilidade); assim, ele é normalmente utilizado para entender o porquê que o usuário aceita ou rejeita a Tecnologia de Informação e como melhorar a aceitação, oferecendo, desse modo, um suporte para prever e explicar a aceitação.

Esse modelo teoriza que uma intenção comportamental do indivíduo para usar um sistema é determinada por duas crenças, facilidade percebida de uso e utilidade percebida, sendo que ambas mediam completamente os efeitos das variáveis externas, como características do sistema, processo de desenvolvimento, treinamento, na intenção de uso (DIAS; ZWICKER; VICENTIN, 2003).

No modelo original do TAM, a facilidade de uso percebida refere-se ao grau de esforço que o usuário acredita que terá de despender para utilizar o sistema que está sendo avaliado. A utilidade percebida diz respeito ao grau de melhoria do seu próprio desempenho que o usuário acredita que receberá caso utilize o sistema avaliado.

A atitude em relação ao uso é o sentimento do usuário de estar favorável ou não em relação a um determinado objeto ou situação, representa o desejo do usuário de utilizar o sistema (SALEH, 2004).

0 uso real do sistema é, de acordo com Dias, Zwicker e Vicentin (2003, p. 17), "a quantidade de uso sobre uma unidade fixa de tempo. Para medir pode-se usar o uso real medido internamente ou perguntar ao usuário".

Por fim, esses mesmos autores elencam algumas limitações do modelo TAM:

- Dificuldade de se pesquisar a aceitação da tecnologia pelo usuário com todas as variáveis envolvidas em seu ambiente real de trabalho;

- Muitos estudos utilizam resposta tipo auto-relato para verificar o uso do sistema, o que pode não refletir a realidade de uso quando o sistema estiver na empresa;

- Geralmente as aplicações não levam em consideração o uso concreto do sistema, mas sim situações de teste do sistema;

- Muitas pesquisas que adotam o modelo TAM utilizam-se de estudantes. Isso se dá pela dificuldade de realizar as pesquisas sempre com pessoas em ambiente de trabalho;

- O modelo não trata com opções. Todos os modelos analisados tratam com o uso de um sistema especifico e não com opções de sistemas;

- O TAM não avalia a questão de recompensas, onde o usuário pode estar disposto a utilizar o sistema devido a obter recompensas;

- O TAM original avalia o uso do sistema sempre pela perspectiva individual do 
usuário e não contempla o usuário trabalhando em equipe e decidindo a escolha do sistema em equipe;

- O modelo não avalia o contexto organizacional em que o sistema está envolvido, não avalia as situações de centralização, conflito, hierarquia, estabilidade, incerteza da empresa.

Acrescentam-se a essas limitações outras duas que inviabilizaram o uso do modelo TAM, tanto o original como as suas variações, nessa pesquisa que se apresenta. 0 primeiro empecilho é que ele não avalia a atitude dos usuários em relação à qualidade que eles esperam e à qualidade que eles percebem receber do produto/serviço, mas sim, entende o porquê que o usuário aceita ou rejeita o objeto de estudo e tenta, por meio dessa compreensão, prever e explicar a aceitação do que está sendo avaliado.

A segunda limitação é que esse modelo avalia a atitude do indivíduo em relação ao produto/serviço em estudo e não a interação que ele tem com esse objeto de avaliação.

\section{Modelo SERVQUAL}

O modelo SERVQUAL é uma escala multidimensional que é utilizada para a avaliação do relacionamento do usuário com o serviço estudado.

O SERVQUAL, de acordo com Zeithaml e Bitner (2003, p. 123), "reflete as cinco dimensões da qualidade dos serviços, sendo que cada dimensão contém múltiplos itens responsáveis pela captação dos atributos fundamentais do serviço". As cinco dimensões da qualidade dos serviços encontradas são: tangibilidade, confiabilidade, presteza [alguns autores referem-se a essa dimensão como responsividade ou compreensão], segurança e empatia.

Tangibilidade são as evidências físicas do produto; instalações, aparência do pessoal, equipamentos utilizados, objetos representativos do serviço [como cartão magnético em bancos e formulários], móveis, escritório, roupas e uniformes e disposição física (PARASURAMAN; ZEITHAML; BERRY apud COSTA FILHO, 1996).

Confiabilidade é a habilidade de se ter o que foi prometido, de se realizar o serviço solicitado sem erros e no prazo, ou seja, de forma precisa e confiável (FARIA, 2003).

Presteza são o desimpedimento e a disposição de entender os problemas e dificuldades dos clientes e responder de uma forma positiva.

Segurança, segundo Parasuraman, Zeithaml e Berry (apud COSTA FILHO, 1996, p. 23), “é a preocupação com o perigo, risco e dúvida; envolve segurança física, segurança financeira, sigilo (em relação a informações pessoais do cliente)". Essa dimensão também é definida por Faria (2003) como a percepção que o cliente tem da habilidade do empregado da empresa em responder às suas necessidades, por exemplo, um técnico em manutenção de televisão que rapidamente encontra e repara o defeito, na hora, na frente do cliente, transmite segurança.

Empatia é a capacidade que o fornecedor do serviço tem em se preocupar com os clientes e lhes oferecer os cuidados e atenção individualizados. Um exemplo pode ser o de um garçom que percebendo as dúvidas de um novo cliente em escolher um prato, leva-o à cozinha e deixa que ele próprio veja como os diversos pratos são preparados para que ele possa escolher o que mais lhe aprouver (FARIA, 2003). 


\section{QUALIDADE DOS INTERNETBANKINGS SEGUNDO CARACTERÍSTICAS DOS USUÁRIOS}

Quanto às limitações do modelo SERVQUAL, Faria (2003) cita as seguintes:

- 0 modelo SERVQUAL mede as expectativas de uma empresa ideal, não de uma empresa específica;

- Essa ferramenta é genérica e, portanto, não mede as dimensões específicas de um ramo de atividade;

- O SERVQUAL é baseado no Modelo Conceitual da Qualidade do Serviço - ou Teoria dos Gaps - que conduz a resultados polarizados. Desde que ambas, a expectativa e a avaliação do serviço, sejam feitas após a realização do mesmo, as medidas das expectativas podem estar polarizadas pela experiência. Para reduzir estes problemas de polarização os questionários SERVQUAL deveriam ser modificados para medir empresas específicas e a medida das expectativas dos clientes necessitaria ser feita antes de os clientes fruírem os serviços, enquanto que a medida da avaliação do serviço deveria ser feita após a fruição dos serviços;

- A qualidade é relativa e o modelo engessa a qualidade em cinco dimensões, dificultando a comparação entre os atributos da qualidade que o mercado esteja necessitando.

Por fim, uma outra limitação que inviabilizou a utilização do modelo original do SERVQUAL para os fins dessa pesquisa, é que esse método foi desenhado para avaliar atitudes dos usuários em relação à qualidade que eles esperam e à qualidade que eles percebem receber apenas dos serviços físicos, ou seja, dos serviços realizados no mundo real, sendo, dessa forma, inadequado para avaliar os serviços virtuais, como é o caso do Internetbanking. Essa inadequação decorre do fato de no modelo original do SERVQUAL existirem características, principalmente na dimensão tangibilidade, que se pretende mensurar, que não são pertinentes nos serviços virtuais, como no caso do item que solicita a opinião do cliente sobre o apelo visual das instalações da empresa, pois como é sabido, os serviços virtuais possuem como prerrogativa a ausência de instalações físicas que possam prestar o mesmo serviço.

Portanto, o modelo SERVQUAL original está descartado; porém, é possível utilizar uma variação desse modelo, adaptando-o para a avaliação da atitude dos clientes em relação à qualidade esperada e percebida como entregue pelos serviços virtuais, que será chamada de E-BANKING.

\section{Modelo E-BANKING}

Realizaram-se adaptações no modelo SERVQUAL para torná-lo útil para a avaliação da qualidade esperada e percebida Internetbankings, o que gerou o modelo E-BANKING.

As mudanças consistiram na retirada ou alteração de alguns atributos que eram somente mensuráveis no mundo físico e no acréscimo de algumas características apontadas como relevantes em estudos realizados por outros autores que pesquisam os serviços via $W e b$.

\section{Tangibilidade}

Os clientes atribuem um enorme valor aos aspectos tangíveis de um serviço, pois são eles que transmitem algo de concreto sobre os serviços, facilitando o entendimento do mesmo. Assim, esses elementos concretos devem ser bem administrados para indicar ao cliente o valor que será entregue com o serviço.

Albertin (2000) cita um exemplo que ilustra a necessidade de adaptação do conceito tangibilidade para o mundo virtual. Ele afirma que no mundo físico, o local físico é muito importante, está ligado à imagem e ao conceito do próprio negócio, sendo muito citado o caso 
dos bancos com seus prédios e agências. Porém, no mundo virtual isto é subvertido, e essa realidade deve ser entendida e assimilada, ou seja, devem-se criar novas alternativas que funcionem como substitutos na função de se reduzir a sensação de abstração dos serviços, por exemplo, a utilização, no mundo virtual, de um site com um design agradável para substituir os prédios como transmissores de valor.

As características adotadas na dimensão tangibilidade do modelo E-BANKING são:

- Consulta e navegação do site;

- Design e layout gráfico;

- Compatibilidade das tarifas dos serviços do netbanking com os benefícios oferecidos;

- Disponibilidade do material associado com os serviços prestados no netbanking;

- Aparência visual do material associado com os serviços prestados no netbanking;

- Velocidade de carregamento dos sites;

- Facilidade e rapidez para se cadastrar;

- Clareza na linguagem do netbanking.

\section{Confiabilidade}

Com a virtualização, diferentemente do que ocorreu com a dimensão tangibilidade, o conceito confiabilidade não precisou sofrer alterações para se tornar aderente com a avaliação de serviços via Web. Assim, a sua definição continua sendo a descrita no modelo original da SERVQUAL.

Embora já qualificada como importante pelo modelo SERVQUAL para avaliação de qualquer serviço, devido ao aspecto abstrato deles, essa dimensão toma maior vulto quando se trata de serviços financeiros via $W e b$. A razão dessa repercussão é que esses serviços são extremamente sensíveis ao erro e aos prazos, pois um zero errado ou o depósito realizado por engano na conta de outro credor, podem custar meses de produção de uma empresa ou então o pagamento de altos juros, igualmente aos prazos, que se não forem cumpridos, podem resultar em pagamento de juros e penhora de bens.

Quanto aos itens utilizados nessa dimensão para avaliar os netbankings, como o SERVQUAL adapta-se bem nesse campo aos serviços via $W e b$, houve a sua adoção apenas como base, com mudanças em relação ao seu formato original. As características adotadas na dimensão confiabilidade do modelo E-BANKING são:

- Cumprimento do serviço no prazo determinado para executá-lo;

- Realização do serviço conforme especificado pelo cliente;

- Execuções de tarefas sem erros do sistema do netbanking e/ou de transação bancária;

- Envio de informações pré e pós a execução dos serviços.

\section{Presteza}

No mundo virtual a dimensão presteza tem a mesma definição atribuída pelo modelo SERVQUAL aos serviços físicos, ou seja, o desimpedimento e a disposição de entender os problemas e dificuldades dos clientes e responder de uma forma positiva.

Essa dimensão ganhou um especial relevo com a virtualização, pois, como observado por Albertin (2000, p. 144) 


\section{QUALIDADE DOS INTERNETBANKINGS SEGUNDO CARACTERÍSTICAS DOS USUÁRIOS}

a habilidade em prover respostas on-line para problemas, por meio de guia de solução, arquivos de problemas normalmente encontrados, interação com correio eletrônico (e no futuro, suporte a áudio e vídeo), disponibilidade 24 horas por dia e 365 dias por ano constrói a confiança e a retenção do cliente. Monitorar como os clientes utilizam essas informações de suporte também provê informações de áreas de melhoria para os produtos atuais, e uma lista de aspectos criticados nos produtos pode ser uma fonte significativa de realimentação para 0 projeto de novos produtos.

Em relação às características utilizadas para avaliar a presteza dos serviços virtuais, o modelo SERVQUAL mostrou-se coerente com a finalidade desse trabalho, exceto no item que avalia se os funcionários da empresa em questão prestam serviços prontamente, pois, por ser o Internetbanking um serviço de auto-atendimento remoto, não há a existência de funcionários que possam executar os serviços desejados no momento de seu uso. Assim, adotou-se o a dimensão presteza do SERVQUAL como base, com alterações em relação à sua estrutura original.

As características adotadas na dimensão presteza do modelo E-BANKING são:

- Boa vontade dos empregados responsáveis pelo netbanking em ajudar seus clientes;

- Interesse da instituição financeira na solução de problemas dos clientes com o netbanking;

- Desimpedimento dos empregados responsáveis pelo netbanking para esclarecer dúvidas dos seus clientes;

- Suficiência das informações contidas nos menus de ajuda e tutoriais (orientações passo-a-passo) do netbanking.

\section{Segurança}

No modelo desenhado para essa pesquisa, segurança dos serviços bancários via Web é a sensação oferecida aos clientes por meio da reputação da instituição financeira responsável pelo netbanking, do desempenho desse serviço virtual e da utilização de soluções que evitem qualquer circunstância, condição ou evento com potencial de causar danos em dados ou recursos de rede na forma de destruição, revelação, modificação de dados etc.

Albertin (2000) comenta que o investimento necessário para deixar o ambiente virtual seguro somente será realizado quando houver volume de utilização que o justifique; de outro modo, somente haverá adoção em massa quando o ambiente for seguro; ou seja, a sensação de segurança é o fator chave para se atingir a quantidade crítica de usuários, o que representaria o sucesso do Internetbanking tanto para entre os clientes quanto entre os bancos.

Quanto aos itens utilizados para quantificar essa dimensão, apenas dois foram utilizados do modelo SERVQUAL, sendo que um deles teve de ser reformulado para tornar mais coerente com a avaliação dos serviços bancários via $W e b$. As características adotadas para mensurar a dimensão segurança do modelo E-BANKING são:

- Ações preventivas dos responsáveis pelo netbanking;

- Acesso aos serviços do netbanking sem restrições decorrentes de problemas técnicos no seu sistema;

- Reputação da instituição financeira responsável pelos serviços de netbanking;

- Segurança das transações via netbanking; 
- Segurança transmitida pelo desempenho do site.

\section{Empatia}

Mesmo após o aparecimento e fortalecimento da corrente que defende a impossibilidade de existência conjunta da personalização e automação, a dimensão empatia é adotada como componente de avaliação dos serviços virtuais e a sua conceituação permanece igual à atribuída pelo SERVQUAL aos serviços físicos, ou seja, é a prestação de cuidados e atenção individualizados ao cliente.

A justificativa para a consideração dessa dimensão é que com o desenvolvimento de uma infra-estrutura de informação e comunicação pública como a Internet, a distância entre clientes e produtores desapareceu, gerando um envolvimento dos consumidores no real processo de concepção dos serviços.

Quanto à composição dessa dimensão, utilizaram-se quatro itens do SERVQUAL, sendo que dois deles foram transformados em um, outro passou por algumas alterações sutis e um foi mantido, sendo apenas transferido da dimensão tangibilidade para a empatia. As características adotadas no modelo E-BANKING para mensurar a empatia são:

- Nível de atenção individual a cada cliente;

- Conveniência dos horários de funcionamento;

- Padrão de excelência no serviço prestado aos seus clientes;

- Preocupação com a identificação das necessidades e dificuldades específicas dos clientes.

\section{Metodologia}

\section{População/Amostra: unidades de análise}

A população de interesse corresponde aos usuários correntes, apenas pessoas físicas, dos serviços de Internetbanking do Banco Abn Amro Real S.A. (Santander), do Banco do Brasil S.A., do Banco Bradesco S.A., do Banco Itaú S.A., ou do Unibanco - União de Bancos Brasileiros S. A, que são as cinco maiores instituições financeiras, no segmento de múltiplos bancos instituições financeiras que podem realizar todas as operações ativas e passivas intrínsecas a cada um dos tipos individuais de instituição (bancos comerciais, investimento, desenvolvimento, etc.) - atuantes na cidade de São Paulo em termos de depósitos totais no mês de junho de 2004, sendo os respectivos montantes de R 115,7 bilhões, $\mathrm{R} \$ 64,3$ bilhões, $\mathrm{R} \$ 36,3$ bilhões, $\mathrm{R} \$ 29,6$ bilhões e $\mathrm{R} \$ 26,9$ bilhões, o que representa 51,5\% dos depósitos do Sistema Financeiro Nacional (BCB, 2004). Ademais, o público-alvo desse trabalho deveria residir na cidade de São Paulo durante o período de coleta dos dados, compreendido entre o segundo semestre de 2005 e o primeiro semestre de 2006.

Foi empregada a amostragem casual simples considerando-se a população como infinita, visto que o número correntistas de Internetbanking no Brasil é de 18 milhões (FEBRABAN, 2008). Com nível de confiança de 95\% e margem de erro de 8\%, gerou-se uma amostra de 150 entrevistas.

\section{0 tipo de pesquisa e forma de coleta dos dados}

Esta é uma pesquisa quantitativa descritiva com a utilização de dados primários.

Foi realizado um levantamento amostral e a forma de abordagem foi por telefone e correio eletrônico. O plano para a obtenção das respostas dos entrevistados consistia em primeiramente realizar uma ligação telefônica direta para os indivíduos sorteados. A partir da 


\section{QUALIDADE DOS INTERNETBANKINGS SEGUNDO CARACTERÍSTICAS DOS USUÁRIOS}

aquiescência deles em participar da pesquisa e da adequação às condições necessárias, executava-se o envio do questionário pelo correio eletrônico. Os entrevistados que se recusassem a participar, eram substituídos aleatoriamente por outros elementos amostrais.

O instrumento de coleta de dados consistiu de um questionário estruturado, não disfarçado e composto somente de perguntas fechadas, no qual foram considerados os atributos apresentados nas seções que compõem o item 2.3.3, referentes às dimensões tangibilidade, confiabilidade, presteza, segurança e empatia do modelo E-BANKING.

\section{Composição da amostra estudada}

A amostra efetiva foi composta de 148 entrevistas, pois houve dois missings decorrentes de questionários mal preenchidos.

Quanto ao perfil sócio-demográfico e de familiaridade com a Internet e o cyberbanking, o respondente dessa pesquisa é, de um modo geral, do sexo masculino com idade entre 26 e 32 anos, com nível de escolaridade superior completo, movimentador de grande volume monetário mensal no netbanking considerado principal, estando acima de $\mathrm{R} \$ 2999$, extremamente acostumado com a Internet, considerando-se um bom conhecedor, favorável ao auto-atendimento, usuário há no máximo 4 anos do netbanking considerado atualmente como principal, o qual é acessado mais de uma vez por semana.

\section{Avaliação do modelo E-BANKING}

Todo modelo de avaliação, necessita-se, para se atingir uma massa crítica de adeptos, comprovação da sua confiabilidade e validade. Um modelo pode ser confiável e não-válido, porém, nunca poderá ser válido e não-confiável (COOPER; SCHINDLER, 2003).

\section{Confiabilidade}

Confiabilidade de um instrumento de medida é a extensão em que suas mensurações estão livres de erro aleatório ou instável (PETER, 1979). Em outras palavras, o instrumento é capaz de produzir resultados consistentes se repetidas mensurações são realizadas. Para que um escore reflita o constructo subjacente, há que se contar com elevada confiabilidade (GULLIKSEN, 1950).

Para a análise da fidedignidade das dimensões do modelo conceitual de gestão de processos, foi utilizado o coeficiente alfa de Cronbach, capaz de revelar quão fortemente os itens de uma escala estão inter-relacionados (TULL; HAWKINS, 1990). Este coeficiente foi calculado para cada uma das cinco dimensões do instrumento de coleta de dados da pesquisa. Por meio desta análise também foi possível avaliar a sensibilidade do coeficiente de Cronbach em cada dimensão, calculando-o seguidamente, com a exclusão de cada aspecto da dimensão e comparando-se os resultados, conforme exibido na tabela 1.

Para a análise da confiabilidade, formularam-se duas hipóteses para cada dimensão, ao formato do exemplo que se apresenta para a tangibilidade:

$\mathrm{H}_{0,1}$ : Não há confiabilidade na mensuração da dimensão tangibilidade para a percepção dos clientes em relação à qualidade entregue pelo netbanking.

H1,1: Há confiabilidade na mensuração da dimensão tangibilidade para a percepção dos clientes em relação à qualidade entregue pelo netbanking. 
Tabela 1

\section{Coeficiente alfa de Cronbach}

\begin{tabular}{|c|c|c|c|c|}
\hline Dimensão & $\begin{array}{c}\text { Coeficiente alfa de Cronbach } \\
\text { baseado em itens } \\
\text { padronizados da dimensão }\end{array}$ & Variável & $\begin{array}{l}\text { Correlação } \\
\text { corrigida item- } \\
\text { total }\end{array}$ & $\begin{array}{l}\text { Alfa de Cronbach } \\
\text { se a variável } \\
\text { específica for } \\
\text { removida }\end{array}$ \\
\hline \multirow{8}{*}{ Tangibilidade } & \multirow{8}{*}{0,8561} & V4 & 0,7447 & 0,8132 \\
\hline & & V7 & 0,5994 & 0,8298 \\
\hline & & V10 & 0,4289 & 0,8549 \\
\hline & & V13 & 0,6243 & 0,8263 \\
\hline & & V16 & 0,5595 & 0,8350 \\
\hline & & V19 & 0,5929 & 0,8301 \\
\hline & & V22 & 0,5978 & 0,8305 \\
\hline & & V25 & 0,6227 & 0,8270 \\
\hline \multirow{4}{*}{$\begin{array}{c}\text { Confiabilidad } \\
\text { e }\end{array}$} & \multirow{4}{*}{0,8016} & V28 & 0,6942 & 0,6663 \\
\hline & & V31 & 0,6404 & 0,6931 \\
\hline & & V34 & 0,6643 & 0,6710 \\
\hline & & V37 & 0,4041 & 0,8465 \\
\hline \multirow{4}{*}{ Presteza } & \multirow{4}{*}{0,8790} & V40 & 0,7894 & 0,8256 \\
\hline & & V43 & 0,8134 & 0,8146 \\
\hline & & V46 & 0,7980 & 0,8228 \\
\hline & & V49 & 0,5696 & 0,9069 \\
\hline \multirow{5}{*}{ Segurança } & \multirow{5}{*}{0,8910} & V52 & 0,6230 & 0,8850 \\
\hline & & V55 & 0,6780 & 0,8390 \\
\hline & & V58 & 0,7700 & 0,8310 \\
\hline & & V61 & 0,8070 & 0,8400 \\
\hline & & V64 & 0,7540 & 0,8560 \\
\hline \multirow{4}{*}{ Empatia } & \multirow{4}{*}{0,7870} & V67 & 0,6897 & 0,6581 \\
\hline & & V70 & 0,3787 & 0,8134 \\
\hline & & V73 & 0,7560 & 0,6476 \\
\hline & & V76 & 0,5555 & 0,7431 \\
\hline
\end{tabular}

O limite inferior geralmente aceito para o coeficiente de Cronbach é 0,70 , apesar de poder ser reduzido para 0,60 em pesquisa exploratória. Em todas as dimensões os valores são aceitáveis, considerando-se a referência de 0,70. Conclui-se que a confiabilidade da escala utilizada no modelo avaliação da qualidade percebida como entregue pelos netbankings, com todas as 25 variáveis, é boa, sendo que o maior e o menor valor do coeficiente Alfa de Cronbach é verificado, respectivamente, nas dimensões segurança $(0,8910)$ e empatia $(0,7870)$. Ademais, as correlações positivas entre as variáveis em cada dimensão mostram que há concordância nas suas classificações, embora sejam moderadas em alguns itens. Assim, as baixas categorias de um item estão associadas às baixas categorias das outras variáveis que compõem o fator, e o mesmo raciocínio para as altas.

Um recurso típico para a melhoria da fidedignidade seria a retirada de itens sem os quais eventualmente a confiabilidade de um modelo seria elevada. Observa-se na tabela 1 que 3 dimensões teriam uma pequena melhoria com a retirada de algumas variáveis, a saber:

- Confiabilidade: o coeficiente passaria de 0,8016 para 0,8465 , com a retirada de V37;

- Presteza: o coeficiente passaria de 0,8790 para 0,9069, com a retirada de V49;

- Empatia: o coeficiente passaria de 0,7870 para 0,8134, com a retirada de V70; 


\section{QUALIDADE DOS INTERNETBANKINGS SEGUNDO CARACTERÍSTICAS DOS USUÁRIOS}

Decidiu-se pela manutenção de tais variáveis devido a dois aspectos: 1) o coeficiente de correlação corrigida item-total é expressivo na V49 (0,5696); 2) o coeficiente alfa de Cronbach destas dimensões é considerado bom mesmo com elas e não ocorreria uma melhoria de classificação dele com a remoção dessas variáveis. Por fim, mantiveram-se a V37 e a V70 porque a correlação corrigida item-total deles, embora baixa, significa que cada item tem uma parte que é comum aos restantes do seu respectivo fator, mas que também explica algo específico. Se as correlações fossem muito elevadas, os dois itens nada teriam de específico, podendo até ser redundantes em relação a outro constituinte da sua dimensão.

Assim, os coeficientes alfa de Cronbach obtidos corroboram a adequação da construção das cinco dimensões que abrangem as principais variáveis de interesse e de análise neste trabalho, podendo-se afirmar que as cinco dimensões podem ser consideradas confiáveis. Logo, a hipótese $\mathrm{H}_{0}$ foi rejeitada em todas as dimensões, ou seja, em cada uma há similaridade (ou homogeneidade) entre as variáveis que as constituem.

\section{Validade}

A validade de um modelo representa o grau em que as percepções encontradas por ele, refletem as percepções reais entre os respondentes que estão sendo testados, e não erros sistemáticos ou aleatórios (AAKER; KUMAR; DAY, 1995), ou seja, deseja-se que a ferramenta de mensuração seja sensível a todas as nuanças de significado na variável e às mudanças nas nuanças ao longo do tempo. (COOPER; SCHINDLER, 2003).

A avaliação da validade de um construto pode ser realizada por meio do cálculo da correlação de suas medidas com a de outro construto que supostamente seja com ele fortemente associado. Esse exame poderá ser feito com a técnica de regressão linear múltipla, na qual os escores dos itens das cinco dimensões do $E$-BANKING serão as variáveis independentes, e a percepção da qualidade global do netbanking será considerada a variável dependente.

Primeiramente aplicou-se a técnica de análise fatorial em cada uma das cinco dimensões de qualidade do netbanking a fim de se reduzir o número de variáveis em cada uma para apenas um fator. Para os cinco fatores obtidos calcularam-se os escores fatoriais. Na tabela 2 encontram-se informações sobre alguns indicadores de qualidade de ajuste das cinco análises fatoriais processadas.

A medida de Kaiser - Meyer - Olkin (KMO) compara as correlações totais entre pares de variáveis com as correlações parciais entre os pares. Quanto mais próxima esta medida estiver de 1, maior a qualidade da análise fatorial. As faixas de classificação dessa medida são: maior ou igual a 0,9 - muito boa; maior ou igual a 0,8 e abaixo de 0,9 - boa; maior ou igual a 0,7 e abaixo de 0,8 - média; maior ou igual a 0,6 e abaixo de 0,7 - razoável; maior ou igual a 0,5 e abaixo de 0,6 - ruim; e abaixo de 0,5 - inaceitável (KAISER, 1974). Os menores valores obtidos correspondem às dimensões confiabilidade $(0,755)$ e empatia $(0,718)$, considerados médios, sendo, portanto, aceitos.

Tabela 2

Resultados da análise fatorial

\begin{tabular}{|c|c|c|r|r|}
\hline Dimensões & KMO & Sig para Bartlett's Test & Eingenvalue & $\begin{array}{l}\text { Variância } \\
\text { explicada }\end{array}$ \\
\hline Tangibilidade & 0,824 & 0,000 & 4,026 & $50,319 \%$ \\
\hline Confiabilidade & 0,755 & 0,000 & 2,547 & $63,679 \%$ \\
\hline Presteza & 0,800 & 0,000 & 2,954 & $73,854 \%$ \\
\hline Segurança & 0,836 & 0,000 & 3,495 & $69,899 \%$ \\
\hline Empatia & 0,718 & 0,000 & 2,479 & $61,977 \%$ \\
\hline
\end{tabular}


0 teste de esfericidade de Bartlett testa a hipótese nula que se refere à matriz de correlação ser a matriz identidade, cujo determinante é igual a 1 (PESTANA; GAGEIRO, 2003). Essa hipótese deverá ser rejeitada para se sinalizar a adequação do uso da análise fatorial. Tal hipótese foi rejeitada nas cinco dimensões do E-BANKING, pois, o nível de significância de todas foi de 0,000 , o que leva à rejeição dela $(p<0,05)$, mostrando portanto que existe correlação entre algumas variáveis.

O eigenvalue consiste na variância total explicada em cada fator. 0 seu raciocínio é que cada fator deve mensurar a variância de no mínimo uma variável se pretender-se retê-lo para interpretação. Cada variável contribui no máximo com o valor 1 para o total do eigenvalue. (HAIR JR. et al., 2006). Assim, somente fatores que tiverem eigenvalue maior do que 1 é que devem ser considerados significantes. Como todas as dimensões tiveram eigenvalue maior do que 1, elas não podem ser descartadas, pois, são consideradas significantes ao representar pelo menos uma variável que a constitui.

A variância total explicada (antes e depois da rotação dos fatores) explicada em cada fator representa a quantidade percentual da variância total das variáveis originais que o fator representa. Reflete a importância de cada fator na substituição das variáveis quanto ao índice de informações preservadas. Em todas as dimensões houve resultados satisfatórios, variando de 50,319 \% (tangibilidade) a 73,854\% (presteza), o que indica que os fatores explicam bem a variabilidade dos dados originais.

Conforme os resultados desses testes, apresentados na tabela 2, houve aprovação e prosseguimento do emprego da técnica análise fatorial e da obtenção de 1 fator para cada dimensão.

Com a aprovação do emprego da análise fatorial sobre as variáveis, deu-se continuidade à avaliação da validade dos construtos do modelo E-BANKING, sendo os escores fatoriais das cinco dimensões considerados como variáveis independentes. Cada usuário de netbanking avaliou, de um modo geral, a qualidade percebida como entregue por esse sistema. Esta percepção foi utilizada como variável dependente na análise de regressão. A tabela 3 apresenta os resultados dos processamentos realizados.

Tabela 3

Resultados da análise de regressão múltipla com os escores fatoriais.

\begin{tabular}{|c|c|c|c|}
\hline Dimensão & Coeficiente Regressão Padronizado Beta & Estatística t & Sig.de t \\
\hline Tangibilidade & 0,459 & 4,402 & 0,000 \\
\hline Confiabilidade & 0,197 & 2,521 & 0,014 \\
\hline Presteza & 0,022 & 0,256 & 0,798 \\
\hline Segurança & 0,014 & 0,148 & 0,883 \\
\hline \multicolumn{2}{|c|}{$0,302 \quad F=49,157$} & 3,748 & 0,000 \\
\hline \multicolumn{2}{|c|}{ Empatia } \\
\hline \multicolumn{2}{|c|}{ Sig F $=0,000$} \\
\hline
\end{tabular}




\section{QUALIDADE DOS INTERNETBANKINGS SEGUNDO CARACTERÍSTICAS DOS USUÁRIOS}

Foram formuladas, para a análise da validade geral do modelo, as seguintes hipóteses:

$\mathrm{H}_{0,6}$ : Não há uma relação linear entre a percepção global da qualidade entregue pelo netbanking e as cinco dimensões consideradas.

$\mathrm{H}_{1,6}$ : Há uma relação linear entre a percepção global da qualidade entregue pelo netbanking e as cinco dimensões consideradas.

E, para a análise da validade das dimensões, formularam-se duas hipóteses para cada uma, ao formato do exemplo que se apresenta para a tangibilidade:

Ho,7: Não há influência da dimensão tangibilidade em uma relação linear entre a percepção global da qualidade entregue pelo netbanking e as cinco dimensões consideradas.

$\mathrm{H}_{1,7}$ : Há influência da dimensão tangibilidade em uma relação linear entre a percepção global da qualidade entregue pelo netbanking e as cinco dimensões consideradas.

$\mathrm{O}$ coeficiente de determinação $\mathrm{R}^{2}=0,732$ indica que as cinco dimensões explicam uma expressiva proporção da variância da percepção global da qualidade entregue pelos netbankings. Este resultado, juntamente com o teste $\mathrm{F}$, evidencia uma relação linear entre a percepção da qualidade entregue pelos netbankings e os escores fatoriais das cinco dimensões. Portanto, rejeita-se $\mathrm{H}_{0,1}$ e confirma-se a validade do constructo destas dimensões.

$\mathrm{Na}$ análise específica de cada dimensão observa-se que apenas tangibilidade, confiabilidade e empatia apresentam influência estatisticamente significante $(p<0,05)$ sobre a percepção global, ou seja, rejeita-se a hipótese nula para esses três fatores, e se aceita como válidas essas dimensões na influência da percepção de qualidade entregue pelo netbanking.

Considerando-se os coeficientes padronizados, as dimensões que mais contribuem para a percepção da qualidade entregue pelos netbankings, em ordem crescente, são: segurança, presteza, confiabilidade, empatia e tangibilidade.

Para confirmar essas observações de validade, efetuou-se o mesmo teste, sendo que dessa vez as médias de cada uma das cinco dimensões foram considerados como variáveis independentes. Esta percepção de cada usuário em relação à qualidade global entregue pelo netbanking continuou como variável dependente na análise de regressão.

As hipóteses para a análise geral do modelo e para a análise de cada dimensão permaneceram as mesmas. Assim, a tabela 4 apresenta os resultados dos processamentos realizados.

$\mathrm{O}$ coeficiente de determinação $\mathrm{R}^{2}=0,739$ confirma que as cinco dimensões explicam uma expressiva proporção da variância da percepção global da qualidade entregue pelos netbankings. Este resultado, juntamente com o teste $\mathrm{F}$, evidencia, realmente, uma relação linear entre a percepção da qualidade entregue pelos netbankings e a percepção de qualidade entregue em cada uma das cinco dimensões do sistema. Portanto, confirma-se a validade do constructo destas dimensões.

$\mathrm{Na}$ análise específica de cada dimensão confirma-se que apenas tangibilidade, confiabilidade e empatia apresentam influência estatisticamente significante $(p<0,05)$ sobre a percepção global, ou seja, rejeita-se a hipótese nula para esses três fatores. 
Tabela 4

\section{Resultados da análise de regressão múltipla com as médias}

\begin{tabular}{|c|c|c|c|}
\hline Dimensão & Coeficiente Regressão Padronizado Beta & Estatística t & Sig.de t \\
\hline Tangibilidade & 0,459 & 4,420 & 0,000 \\
\hline Confiabilidade & 0,214 & 2,679 & 0,009 \\
\hline Presteza & 0,039 & 0,458 & 0,648 \\
\hline Segurança & $-0,009$ & $-0,092$ & 0,927 \\
\hline Empatia & $0,303 \quad$ S,884 & 0,000 \\
\hline \multicolumn{2}{|c|}{ Valor ajustado de $\mathrm{R}^{2}=0,739 \quad 50,766$} & Sig F $=0,000$ & \\
\hline
\end{tabular}

Considerando-se os coeficientes padronizados, as dimensões que mais contribuem para a percepção da qualidade entregue pelos netbankings, permanecem iguais às constatadas com a análise dos escores fatoriais.

Assim, conclui-se, que tanto a análise por escores fatoriais quanto pelas médias de cada dimensão, levará a conclusões convergentes, embora numericamente diferentes.

Por fim, testou-se a correlação de Pearson para os escores fatoriais e para as médias de cada dimensão. Obteve-se que todas as dimensões são estatisticamente relevantes, sendo que entre os escores fatoriais e as médias a correlação mais baixa foi da dimensão presteza, 0,654 e 0,651 , respectivamente. Assim, confirma-se a validade da modelo E-BANKING, pois, realmente há influência de cada uma das cinco dimensões na percepção global dos clientes em relação à qualidade entregue pelo serviço de Internetbanking e há uma relação linear entre a percepção global da qualidade entregue pelo netbanking e as cinco dimensões consideradas.

\section{Percepção de qualidade segundo as características dos respondentes}

Após constatar que o modelo E-BANKING oferece dados confiáveis e válidos, prossegue-se com a análise da percepção de qualidade dos clientes em relação à qualidade entregue pelo Internetbanking.

A análise de correspondência foi executada com o uso de 138 casos, tendo sido descartadas 12 observações devido à falta de dados em uma ou mais das variáveis estudadas. Optou-se pelo uso de apenas duas dimensões por que elas explicam 54,94\% da variância dos dados.

Em relação à capacidade das variáveis de caracterizar cada dimensão, as variáveis freqüência de uso do netbanking, volume monetário médio movimentado mensalmente e tempo de familiaridade com o netbanking citado como principal foram associadas exclusivamente à dimensão 1, enquanto que escolaridade foi associada somente com a dimensão 2 . A variável idade do respondente foi associada às duas dimensões.

Já as variáveis gênero sexual e percepção da qualidade recebida não eram relevantes para nenhuma dimensão, porém, decidiu-se mantê-las para enriquecer a análise dos dados, sendo que a primeira variável foi associada à dimensão 2 e a última, por interesse de relacioná-la com todas as variáveis estudadas, foi associada às duas dimensões. Na tabela 5, são apresentadas as variáveis com as suas respectivas medidas de discriminação em cada 


\section{QUALIDADE DOS INTERNETBANKINGS SEGUNDO CARACTERÍSTICAS DOS USUÁRIOS}

dimensão, sendo que o valor em negrito mostra a associação da variável à dimensão.

Percebe-se que, nas duas dimensões do mapeamento, as variáveis idade, escolaridade e frequência de uso têm o maior poder de discriminação dos conglomerados do que a variável percepção da qualidade recebida, pois, elas ficam mais distantes da origem dos eixos das dimensões.

Tabela 5

Medidas de discriminação das variáveis em cada dimensão

\begin{tabular}{|c|c|c|c|}
\hline Variável & Dimensão 1 & Dimensão 2 & Média \\
\hline Gênero Sexual & 0,123 & $\mathbf{0 , 1 8 7}$ & 0,155 \\
\hline Idade & $\mathbf{0 , 4 5 3}$ & $\mathbf{0 , 4 3 3}$ & 0,443 \\
\hline Escolaridade & 0,220 & $\mathbf{0 , 5 3 8}$ & 0,379 \\
\hline Volume Movimentado & $\mathbf{0 , 6 3 1}$ & 0,031 & 0,331 \\
\hline $\begin{array}{c}\text { Tempo de } \\
\text { Familiaridade }\end{array}$ & $\mathbf{0 , 4 3 8}$ & 0,016 & 0,227 \\
\hline Freqüência de Uso & $\mathbf{0 , 3 8 2}$ & 0,206 & 0,294 \\
\hline Qualidade Percebida & $\mathbf{0 , 0 6 3}$ & $\mathbf{0 , 1 2 4}$ & 0,093 \\
\hline \% da Variância & 33,004 & 21.936 & 27,470 \\
\hline
\end{tabular}

Ao analisar a quantificação das categorias, detalhada na tabela 6 e representada na figura 1 , percebe-se que a primeira dimensão integra as pessoas que possuem mais de 32 anos, movimentam mensalmente, em média, mais de R\$ 1500 pelo netbanking, utilizam o seu principal sistema há mais de 4 anos, sendo que o acessam mais de 1 vez por semana e que tem uma alta percepção da qualidade recebida, em oposição a um grupo de usuários com idade até 32, que movimentam mensalmente, em média, menos de $\mathrm{R} \$ 1500$ pelo netbanking, são pouco familiarizados com o sistema, possuem baixa freqüência de uso e percepção da qualidade entregue.

Os grupos formados nessa dimensão demonstram haver uma relação positiva entre familiaridade com o netbanking, percepção de qualidade entregue e taxa de uso do sistema, sendo que quando a primeira é baixa, acaba-se gerando um ciclo de causa e efeito destrutivo para o sistema utilizado, o qual terminaria com o cliente desistindo de utilizar esse canal de serviço ou optando pelo netbanking de outra instituição. 
Tabela 6

\section{Quantificação das categorias em cada dimensão}

\begin{tabular}{|c|c|c|c|}
\hline Variável & Categoria & Dimensão 1 & Dimensão 2 \\
\hline \multirow{2}{*}{ Gênero Sexual } & Masculino & 0,299 & 0,369 \\
\hline & Feminino & $-0,413$ & $-0,508$ \\
\hline \multirow{4}{*}{ Idade } & Até 25 anos & $-1,123$ & 1,036 \\
\hline & 26 a 32 anos & $-0,076$ & $-0,818$ \\
\hline & 33 a 43 anos & 0,512 & 0,053 \\
\hline & Mais de 43 anos & 0,608 & $-0,129$ \\
\hline \multirow{3}{*}{ Escolaridade } & Até Segundo Grau & $-0,825$ & 1,395 \\
\hline & Superior Completo & 0,031 & $-0,507$ \\
\hline & Pós-Graduação & 0,478 & $-0,185$ \\
\hline \multirow{3}{*}{ Volume Movimentado } & Abaixo de $\mathrm{R} \$ 1500$ & $-0,994$ & $-0,131$ \\
\hline & De R\$ 1500 a R\$ 2999 & 0,031 & $-0,139$ \\
\hline & $\mathrm{R} \$ 3000$ ou mais & 0,892 & 0,230 \\
\hline \multirow{2}{*}{$\begin{array}{c}\text { Tempo de } \\
\text { Familiaridade }\end{array}$} & Até 4 anos & $-0,598$ & 0,114 \\
\hline & Mais de 4 anos & 0,733 & $-0,140$ \\
\hline \multirow{2}{*}{ Freqüência de Uso } & Até 1 vez por semana & $-0,664$ & $-0,489$ \\
\hline & Mais de 1 vez por semana & 0,574 & 0,423 \\
\hline \multirow{3}{*}{ Qualidade Percebida } & Até 7 & $-0,317$ & $-0,470$ \\
\hline & De 7,1 a 8 & 0,073 & 0,313 \\
\hline & Acima de 8 & 0,289 & 0,198 \\
\hline
\end{tabular}




\section{QUALIDADE DOS INTERNETBANKINGS SEGUNDO CARACTERÍSTICAS DOS USUÁRIOS}

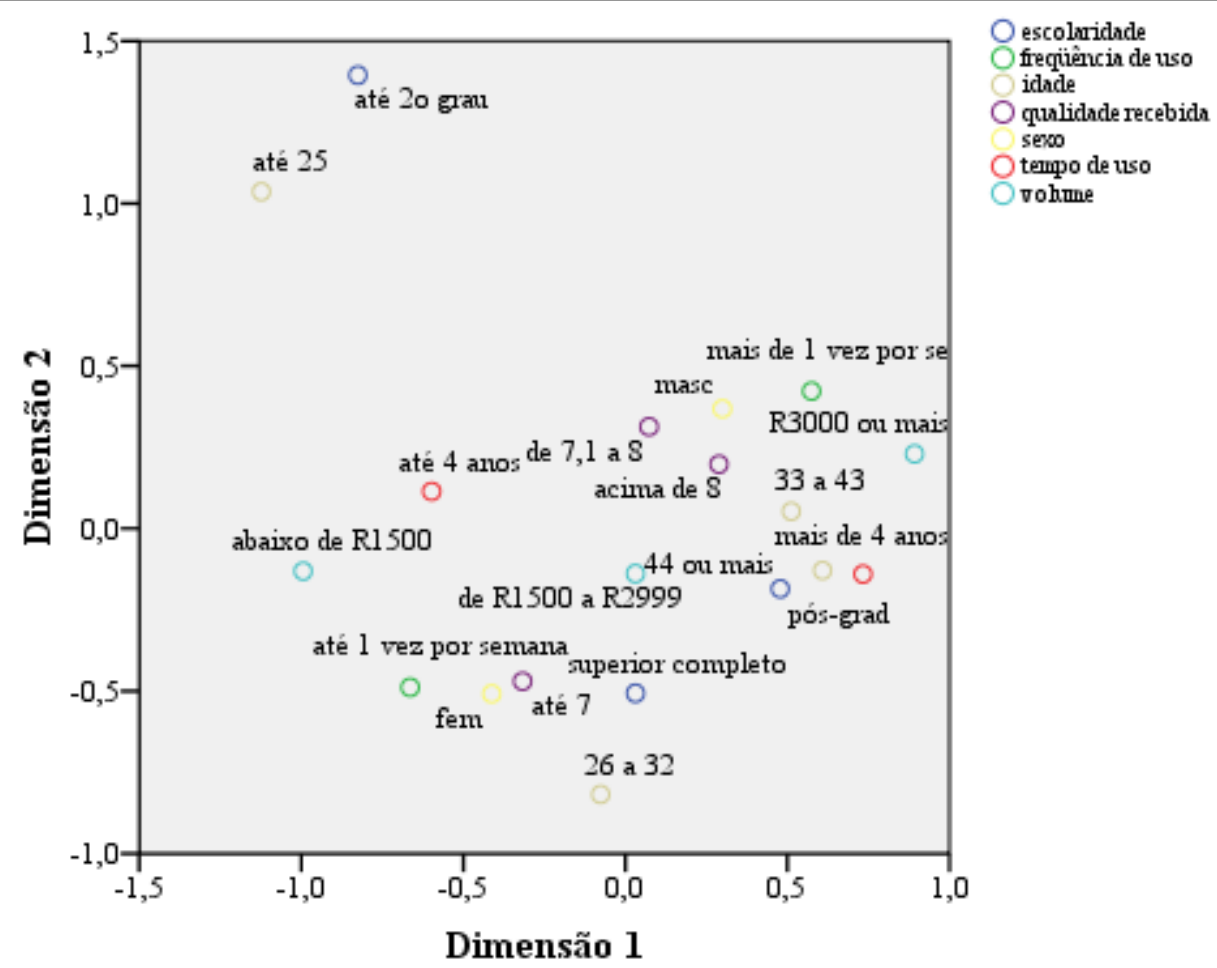

Figura 1: Distribuição das categorias nas duas dimensões

A segunda dimensão associa os usuários do sexo masculino, com idade até 25 anos ou de 33 a 43 anos, formação escolar até o segundo grau e com alta percepção da qualidade entregue pelo Internetbankig, em oposição àqueles do sexo feminino, entre 26 e 32 anos ou mais de 43 anos, com superior completo ou pós-graduado e com baixa percepção da qualidade entregue por esse canal de serviço. Esses grupos criam a possibilidade de haver uma relação inversa entre formação escolar e percepção da qualidade entregue pelo netbanking, indicando que uma maior formação escolar do usuário pode levar a uma maior exigência de qualidade. Ademais, eles mostram que a mulher é mais exigente em relação à qualidade desse serviço.

Ao analisar as duas dimensões em conjunto, é possível constatar que as percepções de qualidade recebida são maiores entre os homens, com idade de 33 a 43 anos, que usam o netbanking mais de uma vez por semana e movimentam mais de R\$3000 por mês nesse serviço. Observa-se também que as menores percepções de qualidade recebida são atribuídas por pessoas do sexo feminino, com idade entre 26 e 32 anos, que utilizam o banco virtual menos de uma vez por semana e movimentam, em média, menos de $\mathrm{R} \$ 1500$ por mês nesse canal.

Além disso, o mapeamento revela que os mais jovens com escolaridade até segundo grau não apresentaram associação mais forte com uma faixa específica de qualidade recebida, podendo-se concluir que a distribuição das suas opiniões é homogênea em todos os níveis de qualidade percebida como entregue pelo cyberbanking.

Finalmente, as percepções de qualidade recebida são maiores entre os entrevistados com idade entre 33 e 43 anos. 0 porquê dessa preferência pelo cyberbanking entre os homens de meia-idade é motivo para estudos futuros, mas aventa-se a hipótese de que seja devido ao fato de que os custos tangíveis e intangíveis das pessoas nessa faixa etária sejam menores e, consequentemente, a faixa de tolerância deles com a qualidade recebida seja maior do que em comparação com as pessoas na faixa etária entre 26 e 32 anos, que frequentemente encontram-se em plena fase de crescimento profissional e assim possuem menor tempo 
disponível, o que leva ao estabelecimento de níveis de excelência maior para os serviços a fim de se evitarem desperdícios de recursos. Esse pensamento estaria de acordo com a observação, realizada por Saraiva (2010), de que os usuários mais jovens são exigentes e esperam inovações constantes.

\section{Considerações finais}

Com acirramento da competição comercial e a queda substancial da taxa de inflação, os bancos estão diante de uma situação que lhes exige a inovação em termos de produtos e serviços, a busca por custos reduzidos e o foco no cliente, a fim de fidelizá-lo e aumentar o número de transações realizadas por ele.

Esse novo paradigma tem empurrado os bancos para as fronteiras digitais, em busca de um canal que tenha maior interação com os clientes e um baixo custo. Assim, deu-se o aparecimento dos serviços de Internetbanking, que além de agregar esses dois interesses, pode ainda oferecer ao usuário o conforto de poder utilizar os serviços bancários de qualquer lugar e com um horário estendido.

Porém, essas vantagens já têm sido observadas por todo o setor bancário e também por setores relacionados, o que trouxe competição acirrada também para o mundo virtual, em decorrência de uma profusão de sites que oferecem serviços bancários e financeiros virtuais, tirando, dessa forma, das instituições pioneiras no serviço a vantagem do monopólio. Para poder sobreviver nesse novo ambiente, os bancos precisam desenvolver novas vantagens competitivas a fim de se destacarem aos olhos do mercado.

Com o objetivo de se alcançar a vantagem competitiva no mercado bancário virtual, os bancos deverão primeiramente identificar qual é a percepção dos seus clientes em relação ao desempenho atual do seu netbanking e quais são os atributos considerados importantes pelos consumidores para se obter excelência na entrega dos serviços bancários virtuais, otimizando, deste modo, o investimento de recursos para melhorar o sistema nos itens "ganhadores de cliente".

Dessa forma, nesta pesquisa, procurou-se fornecer maiores subsídios para os bancos saberem como se comportarem e posicionarem os seus serviços no mundo virtual, por meio do estudo da percepção dos clientes em relação ao desempenho dos cyberbankings e analisar qual a importância que eles atribuíam às cinco dimensões consideradas essenciais a esses serviços. Para esse fim, construiu-se o modelo E-BANKING, que avalia os serviços bancários virtuais, e utilizaram-se técnicas de análise multivariada de dados como a análise fatorial, de regressão, de correspondência e alfa de Cronbach, com o objetivo de levantar informações a partir dos dados primários obtidos.

Pelos resultados apresentados ao longo do trabalho, comprovou-se que o modelo E-BANKING é válido e confiável, o que demonstra a sua utilidade para a mensuração da percepção da qualidade/desempenho dos Internetbankings.

De acordo com o encontrado, para melhorar a sua avaliação junto aos usuários, é essencial que os bancos invistam nas dimensões de tangibilidade e empatia da sua versão virtual, pois são as características mais importantes na opinião dos entrevistados. Assim, sites rápidos, claros e de fácil navegação são importantes, tal qual tarifas justas para os serviços ofertados, disponibilidade de documentos referentes aos serviços prestados, e foco no relacionamento com o cliente, como atenção e experiência de uso individualizada, preocupação sincera com as dificuldades e necessidades dele e oferta de serviços com excelência.

Os resultados mostram que usuários familiarizados com o banco virtual tendem a utilizá-lo 


\section{QUALIDADE DOS INTERNETBANKINGS SEGUNDO CARACTERÍSTICAS DOS USUÁRIOS}

mais, movimentar quantias maiores e atribuir notas melhores à sua qualidade, formando-se aí um ciclo virtuoso. Assim, avaliando-se conjuntamente os achados desse estudo, conclui-se que uma melhoria da facilidade e navegabilidade (atributos relacionados à tangibilidade do serviço), atendendo-se as necessidades dos clientes (característica ligada à empatia), pode aumentar a familiaridade e percepção de qualidade recebida dos usuários, resultando em uma maior taxa de adoção e uso do sistema e crescimento do volume de transação mensal.

E, embora empatia e tangibilidade sejam dimensões desejadas pelos clientes e de diferenciação para esses bancos virtuais, segurança, presteza e confiabilidade ainda são dimensões necessárias para um cyberbanking se integrar à lista de consideração dos usuários. Portanto, ações preventivas dos responsáveis pelo netbanking, segurança das transações via este sistema, boa vontade dos empregados em ajudar os clientes, interesse da instituição financeira na solução de problemas deles e cumprimento do serviço no prazo determinado para executá-lo e conforme especificado pelo usuário são características básicas já esperadas pelo cliente quando este opta por utilizar um Internetbanking, não possuindo muito poder para diferenciá-los, porém tendo a capacidade de eliminá-los da consideração do usuário.

Essa melhoria da qualidade percebida é imperiosa, pois, os clientes que possuem maior formação escolar e que se espera que sejam os de maior renda mensal, são os mais exigentes em relação à qualidade entregue pelos netbankings, exigindo, desse modo, melhorias para ampliar a sua adoção ou aumento do uso. Com a identificação de características dos usuários que estão relacionadas com a satisfação/melhor relação com o Internetbanking, é possível construir-se um scorecard de características pessoais dos clientes e, desta maneira, oferecer serviços com qualidade e/ou preços diferenciados, de acordo com a pontuação obtida.

Por fim, esta pesquisa pretendeu contribuir para o melhor entendimento da percepção dos clientes dos netbankings em relação à qualidade entregue por esse meio de relacionamento e considera-se que esse objetivo proposto foi alcançado. E deixa-se o alerta que as instituições financeiras terão muito a fazer se quiserem obter o nível de excelência necessário para transformar o netbanking em um canal preferencial para a realização dos serviços bancários, o que levaria ao alcance da massa crítica exigida para possibilitar a lucratividade desse serviço.

\section{Limitações da pesquisa}

A reduzida existência de estudos sobre o mercado bancário virtual brasileiro limitou a possibilidade de comparações das informações obtidas nessa pesquisa com os resultados de outros trabalhos e, também, o aprofundamento de alguns aspectos levantados durante a revisão bibliográfica.

Também, ao ser o tema desse estudo a percepção dos clientes em relação à qualidade entregue pelos Internetbankings, o fato de o campo ter sido realizado na cidade de São Paulo é um fator limitante, uma vez que clientes de todas as regiões do Brasil poderiam ter sido consultados sobre as suas percepções em relação a esses serviços, pois, embora o netbanking seja o mesmo para todo o país, devido a diferenças culturais entre as regiões poderiam ocorrer percepções diferentes. Assim, para que houvesse uma representatividade ideal, indivíduos de todas as cidades brasileiras deveriam ter as mesmas chances de serem abordados, o que possibilitaria, desse modo, a generalização dos resultados dessa pesquisa para o cliente de netbanking do Brasil todo, e não apenas da cidade de São Paulo.

Ademais, devido à delicadeza do tema para os entrevistados, decorrente do aumento de crimes virtuais, à falta de cultura do brasileiro em participar de pesquisas e à extensão do questionário, muito da riqueza das análises perdeu-se, pois, ou o entrevistado respondia de 
uma forma padrão ou fornecia o mínimo de dados necessários, o que impossibilitou resultou em uma amostra válida muito reduzida para algumas análises e, dessa forma, impossibilitou reflexões mais profundas a respeito do tema.

Por fim, estas limitações comentadas acima são importantes de se ter em mente quando da leitura dos resultados da pesquisa de campo, pois ficam bem claros o alcance e a extensão destes últimos. No contexto desta pesquisa de iniciação científica, a pesquisa de campo tem a importante função de fornecer elementos para o entendimento do problema e proposição de novas questões sobre o tema.

\section{Propostas de estudos posteriores}

Durante a revisão teórica e análise de dados deparou-se com alguns questionamentos com relação ao tema serviços bancários via Internet que não são respondidos plena e adequadamente pelos textos produzidos até a data de conclusão desse trabalho. Tais interrogações são apresentadas, aos interessados em aumentar a gama de escritos e aprofundar-se no tema, como propostas para pesquisas posteriores: 1) Os clientes que utilizam o netbanking e que preferem o auto-atendimento possuem uma percepção mais favorável da qualidade entregue por esse sistema em relação aos usuários que preferem o atendimento pessoal? 2) Em que medida a declarada falta de segurança nos sistemas bancários via Web pode realmente atrasar o processo de adoção desse meio? 3) Em que medida o baixo desempenho em dimensões como tangibilidade, empatia e confiabilidade, consideradas pelos clientes como importantes para os serviços do banco virtual, pode realmente atrasar o processo de adoção desse meio? 5) A percepção, dos clientes de todo o Brasil, em relação à qualidade entregue pelos Internetbankings é a mesma que a do cliente residente da cidade de São Paulo? 6) Usuários de Internetbanking de outros países têm a mesma percepção que os clientes de São Paulo em relação à qualidade entregue por esses sistemas?

\section{Referências}

AAKER, D. A.; KUMAR, V.; DAY, G. S. Marketing research. 5 ed. New York: John Wiley \& Sons, Inc., 1995.

ALBERTIN, A. L. Comércio eletrônico: modelo, aspectos e contribuições de sua aplicação. 2 ed. São Paulo: Atlas, 2000.

BADER, M. Flexibilidade e inovação na indústria bancária: o banco virtual. 1999. 323p. Tese (Doutorado em Engenharia de Produção) - Escola Politécnica, Universidade de São Paulo, São Paulo.

BANCO CENTRAL DO BRASIL - BCB. Ranking dos bancos-posição dos balancetes de junho ou dezembro: (doc. 4010), critério de depósitos totais no mês de junho de 2004. Disponível em << http://www5.bcb.gov.br/ixpress/cosif/Opcao3/Indice.dml >>. Acesso em 20 out. 2004.

COOPER, D. R.; SCHINDLER, P. S. Métodos de pesquisa em administração. 7 ed. Porto Alegre: Bookman, 2003.

COSTA FILHO, B. A. Automação Bancária: uma análise sob a ótica do cliente. 1996. 384p. Dissertação (Mestre em Administração) - Faculdade de Economia, Administração e Contabilidade, Universidade de São Paulo, São Paulo.

DAVIS, F. A Technology Acceptance Model for empirically testing new end-user information systems: theory and results. Tese de doutorado, Sloan School of Management 


\section{QUALIDADE DOS INTERNETBANKINGS SEGUNDO CARACTERÍSTICAS DOS USUÁRIOS}

Science, Massachusetts Institute of Technology, 1986

DIAS, M. C.; ZWICKER, R.; VICENTIN, I. C. Análise do modelo de aceitação de tecnologia de

Davis. Revista SPEI, Curitiba, v. 4, $\mathrm{n}^{\circ}$ 2, p. 15-23, jul./dez. 2003. Disponível<<http://Web.spei.br:8081/faculdades/revista/revista_V4_n2/analise_modelo.pdf >>. Acesso em: 28 fev. 2006.

DINIZ, E. H. Uso da Web nos serviços financeiros. São Paulo: Núcleo de pesquisas e publicações - Fundação Getúlio Vargas (EASP/FGV/NPP), 2001. 198 p.

FARIA, C. A. Servqual: uma ferramenta para medir a qualidade dos serviços. 2003. Disponível em << http://www.merkatus.com.br/10_boletim/26.htm >>. Acesso em: 12 mai. 2004.

FEDERAÇÃO BRASILEIRA DOS BANCOS - FEBRABAN. Relatório anual 2008. 2008. Disponível em <<http://www.febraban.org.br/bd/FRProjetos.asp?id_grupo=760\&id_assunto=350\&id_pasta $\mathrm{MA}=52 \& i d \_a s s u n t o M A=350 \% 20 \& i d \_a s s u n t o M E=0 \& i d \_i t e m=0>>$. Acesso em: 02 nov. 2013.

FORTUNA, E. Mercado financeiro: produtos e serviços. 15 ed. Rio de Janeiro: Qualitymark Editora, 2002.

GULLIKSEN, H. Theory of Mental Tests. New York: John Wiley \& Sons, 1950

HAIR JR., J. F.; BLACK, W. C.; BABIN, B. J.; ANDERSON, R. E.; TATHAM, R. L.; Multivariate data analysis. 6 ed. Upper Saddle River: Prentice Hall, 2006.

KOTLER, P. Administração de marketing. 10 ed. São Paulo: Prentice Hall. 2000.

OHIRA, M.L.B.; SCHENKEL, M. B. C.; SILVEIRA, C. Critérios para avaliação de conteúdos dos sites dos arquivos públicos estaduais do Brasil. In: SIMPÓSIO INTERNACIONAL DE PROPRIEDADE INTELECTUAL, INFORMAÇÃO E ÉTICA, 2, 2003, Florianópolis. Anais eletrônicos... Florianópolis: UFSC, 2003. Disponível em $<$ www.ciberetica.org.br/trabalhos/anais/65-100-p1-100.pdf >>. Acesso em 23 ago. 2005.

PETER, J. P. Reliability: a review of psychometric basics and recent marketing research. Journal of Marketing Research, Feb. 1979.

SARAIVA, J. Geração on-line. Valor Econômico. São Paulo, 09 jun. 2010. Especial Tecnologia bancária, p. 1.

SALEH, A. M. Adoção de tecnologia: um estudo sobre o uso de software livre nas empresas. 2004. 149p. Dissertação (Mestre em Administração) - Faculdade de Economia, Administração e Contabilidade, Universidade de São Paulo, São Paulo.

TANAAMI, K. M. Lucro virtual. Revista EXAME. Ed. 778. São Paulo: Ed. Abril. 11 nov. 2002.

TULL, D. S.; HAWKINS, D. I. Marketing research: measurement and method. New York: Macmillan, 1990.

ZEITHAML, V. A.; BITNER, M. J. Marketing de serviços: a empresa com foco no cliente. 2 ed. Porto Alegre: Bookman, 2003. 